\title{
Early Childhood Educators' Perceptions of Their Emotional State, Relationships with Parents, Challenges, and Opportunities During the Early Stage of the Pandemic
}

\author{
Nathalie Bigras $^{1}$ (D) $\cdot$ Lise Lemay $^{1} \cdot$ Joanne Lehrer $^{2} \cdot$ Annie Charron $^{1} \cdot$ Stéphanie Duval $^{3} \cdot$ Christelle Robert-Mazaye $^{2}$. \\ et Isabelle Laurin ${ }^{4}$
}

Accepted: 2 June 2021 / Published online: 11 June 2021

(C) The Author(s), under exclusive licence to Springer Nature B.V. 2021

\begin{abstract}
This article presents a study about the impact of COVID-19 on childcare center educators in Quebec (Canada). Regulated childcare services were closed due to the pandemic between March 16 and May 31, 2020, in areas considered "hot" (highly affected by the pandemic). During this time, some centers were transformed into "emergency childcare services" available to parents considered to be essential workers. Therefore, few children attended, and most educators worked remotely. In May 2020, 372 educators completed an online questionnaire regarding their emotional state, challenges, and learning opportunities. Results indicate that half of the respondents reported a decrease in their level of well-being at work and an increase in their stress level. Educators working remotely were more likely to report a lower level of stress than when working with children at daycare (36.1\% vs 19.7\%). Despite these findings, educators estimated that the parents who used their emergency childcare service presented either high $(37.7 \%)$ or average $(32.2 \%)$ levels of wellbeing. The factors that educators identified as facilitating their interactions with families included parental recognition of their work (11.68\%) and direct contact with them (12.62\%). While many tasks accomplished at home were done for the first time during this period (i.e., creating video capsules for children and parents, virtual meetings with children and colleagues), a large majority of respondents reported that these tasks made them feel useful. Working at their own pace (34.7\%) was seen as the principal advantage of remote working. Finally, $28.84 \%$ mentioned that the reduced ratio (1:2 or 1:3) was a facilitating factor that they would like to maintain during the upcoming reopening phase. The discussion uses the Job Demands and Resources theoretical framework (Bakker and Demerouti in Wellbeing 3(2):1-28, 2014; Dicke et al. in J Occupat Health Psychol 23(2): 262-277, 2017) to explain the educators' work-related demands and emotional state in both remote and CPE working pandemic contexts. In conclusion, we argued that this pandemic reveals the complexity, but also the essential nature of the work of early childhood educators, in particular by identifying their needs for support and recognition essential to their professional commitment.
\end{abstract}

Keywords COVID-19 effects $\cdot$ Educators $\cdot$ Wellbeing $\cdot$ Stress $\cdot$ Remote work

Nathalie Bigras

bigras.nathalie@uqam.ca

1 Faculté des Sciences de l'éducation, UQAM, Québec, Canada

2 Faculté des Sciences de l'éducation, Université du Québec en Outaouais, Québec, Canada

3 Faculté des Sciences de l'éducation, Université Laval, Québec, Canada

4 Direction de la Santé Publique de Montréal, CIUSS centre-sud, Montréal, QC, Canada

\section{Introduction}

The coronavirus SARS-CoV-2 (COVID-19) epidemic was declared a global pandemic by the World Health Organization (WHO, 2020) on March 11, 2020. On Friday, March 13, 2020, the government of Quebec ([GQ] Canada, 2020) declared a public health emergency (GQ, 2020a). Confinement and closure of several facilities, including Early Childhood Education and Care (ECEC) services was announced. However, in order to maintain a number of essential services, the government established emergency childcare for the children of health care workers (e.g., doctors, nurses) and essential social services (e.g., 
police, firefighters) and designated not-for-profit ECEC services to offer them, operating at about $30 \%$ of their regular capacity. To limit the economic impact of these government decisions, the government mandated that all early childhood educators receive their full pay throughout this period, despite the reconfiguration of ECEC services. A gradual reopening of ECEC services took place from mid-May to mid-July (GQ, 2020b), operating from 30 to $100 \%$ of their capacities. To our knowledge, very few studies have documented the impact of the pandemic on the emotional state of early childhood educators to date, as well as on their working conditions during the early pandemic, given the unique and unprecedented context caused by COVID-19. The purpose of the study is to describe the impact of the pandemic on the emotional state of early childhood educators and the challenges they faced within the Quebec childcare context.

\section{The Emergency Childcare Services Period}

During the early pandemic, emergency childcare services (ECS) faced many socio-emotional and structural challenges, while receiving limited resources. Socioemotionally, the rapid integration of essential workers' children who did not attend the ECEC services prior to the confinement period created adjustment challenges for children and their parents, as well as for early childhood educators. Structurally, there was a work overload associated with new pandemic tasks, such as regular disinfection (twice a day) of educational and environmental materials (e.g., door handles, shelves, chairs, and equipment). Furthermore, in addition to the new forms of contact with children and their families (e.g., parents were met outside and no longer permitted to enter the building), institutions had to dramatically change their ways of operating (e.g., new parents were unable to visit the ECEC service prior to registration and a gentle transition consisting of gradual entry was impossible to implement). At the same time, the confinement impacted early childhood educators' availability, as they worked mostly from home on remote work activities, going into the centres once or twice a week to take turns caring for a reduced number of children, most of whom were unknown to those early childhood educators. As a result, they had to familiarize themselves with many new remote learning activities (e.g., online professional meetings, phone calls to quarantine, the creation of short pedagogical videos [video capsules] for children and parents, participation in online training, professional readings). These multiple adjustments required a good deal of flexibility and had to be made in the midst of a climate of urgency and fear of catching and transmitting the virus, which could greatly affect their emotional state at work.

\section{The Emotional State of Early Childhood Educators}

The concept of emotional state incorporates both work stress and work, and can vary depending on working conditions. Early childhood educators are responsible for providing quality services to children and families (Quebec's Ministry of Family, [MF] 2019, 2020; Ryan \& Whitebook, 2012). More precisely, they interact with children on a daily basis, in order to meet their needs and support their development (Bigras et al., 2020). Early childhood educators also communicate daily with parents and co-workers to meet children's needs and to support their families (Ryan \& Whitebook, 2012). In particular with parents, their role is to establish and support a partnership relationship "in which the parent and educator mutually recognize one another's expertise and share distinct and complementary knowledge required to ensure the child's adequate care" (Cantin \& Morache, 2015, p. 15). In the context of a pandemic, this partnership relationship is likely to be affected, in particular due to a possible deterioration of early childhood educators' (and parents') emotional states, including their wellbeing at work, while everyone faces new challenges and concerns, even fears, during this period of uncertainty (Corr et al., 2014).

Wellbeing at work generally involves notions of employee engagement, job satisfaction, environmental control, workplace relations, support, autonomy, development and potential development, as well as physical and mental health (Cumming \&Wong, 2019; Hall-Kenyon et al., 2014; Ryff $\&$ Keyes, 1995; Voci et al., 2019). The literature suggests that there are some factors that affect wellbeing at work, including the level of stress experienced at work (Cumming \& Wong, 2019; Rothmann, 2008).

Stress is often used as an indicator of a low level of early childhood educators' wellbeing (Jones et al., 2019). In this regard, Corr et al. (2014) conducted a study with early childhood educators and resource people indicating that a high level of stress at work leads to less appropriate emotional regulation strategies, resulting in a reduction in wellbeing at work. According to the WHO (Leka et al., 2004), stress at work is defined as a set of reactions in the presence of a gap between the demands and pressures placed on the employee and the employee's resources. This discrepancy between demands and resources calls into question the employee's ability to cope with work-related demands and could affect his or her personal health, whether physically (e.g., musculoskeletal problems and cardiovascular disease), mentally (e.g., burnout and depression) (Curbow et al., 2000; Roberts et al., 2019), or related to family and social functioning (e.g., work-life balance) (Burman \& Goswami, 2018). 


\section{Pandemic Effects on Emotional State}

Recent cross-sectional studies (Blouin-Genest et al., 2020; Institut national de santé publique du Québec, [INSPQ] (2020; Jiang et al., 2020) demonstrate that, in the general population, the COVID-19 pandemic increased individuals' levels of distress, anxiety, stress, and depressive symptoms. Specifically, two systematic literature reviews revealed that many individuals experienced high levels of psychological distress (from 34.43 to $38 \%$ ), post-traumatic stress ( $7 \%$ to $53.8 \%)$, stress $(8.1 \%$ to $81.9 \%)$, anxiety symptoms $(6.33 \%$ to $50.9 \%$ ), and depression (from 14.6 to $48.3 \%$ ) (Salari et al., 2020a, b; Xiong et al., 2020). Similarly, Jiang et al. (2020) assert that the pandemic has produced symptoms of post-traumatic stress disorder, particularly among women and people with responsibilities for or who have concerns about their friends or families. In Quebec, a study of 1000 participants in the general population found that between March and May 2020, one in ten individuals experienced psychological distress and perceived their mental health as fair or poor (INSPQ, 2020). In addition, about four out of ten participants reported experiencing increased levels of worry and anxiety (INSPQ, 2020). Finally, a study conducted in the fall of 2020 among 6261 adults from seven regions of Quebec revealed that one in five had clinical symptoms of generalized anxiety disorder or major depression associated with the pandemic (Blouin-Genest et al., 2020). These rates are comparable to those observed in the community of Fort McMurray (Alberta), 6 months after the 2016 wildfires (Blouin-Genest et al., 2020). Thus, given the impact of the pandemic on the mental health of the general population, one can question the state of the early childhood educators who were designated essential service workers and, as such, directly experienced the daily consequences of the pandemic during the period of ECS.

\section{The Effects of Remote Work}

Many early childhood educators experienced remote work for the first time during the ECS period. This new mode of working was not chosen, nor did participants have time to prepare for it. However, it may be closely related to early childhood educators' emotional state, as well as their relationships with parents. Generally, remote work was implemented to ensure the health and safety of employees in the context of a pandemic, while allowing them to meet their professional obligations (Hamouche, 2020). It has benefits, as well as disadvantages, for workers (Hamouche, 2020). In terms of benefits, Johnson et al. (2020) point out that the flexibility associated with remote work would facilitate the planning and adjustment of working hours for family tasks, which would improve worker control and autonomy, while preventing anxiety and depression during abrupt transitions.
Baert et al. (2020) add that remote work during COVID19 has generally increased job satisfaction and efficiency, concentration, and work-life balance, while reducing workrelated stress and the risk of burnout. Nevertheless, there are disadvantages to remote work, such as social isolation and loneliness, particularly related to the decrease in interactions between colleagues, and an increase in family conflicts, particularly concerning work-family balance (Johnson et al. 2020). In the same vein, in her literature review about remote work during COVID-19, Hamouche (2020) identified difficulties in demarcating borders between private and professional life, therefore increasing workloads (e.g., hours spent working). This challenge was also observed by Del Boca et al. (2020), in a study on the effects of remote work in Italy during the spring 2020 confinement, revealing negative impacts on employee mental health, particularly caused by social isolation associated with a high risk of psychological distress and depression. For their part, Baert et al. (2020) identified a negative impact on relationships with colleagues and employers. Finally, Hamouche (2020) and Baert et al. (2020) revealed that remote employee stress level was higher when they have children in their care at home, due to school closures during the confinement.

\section{Theoretical Model of Work}

Our study is based on the Job Demands and Resources model (Bakker \& Demerouti, 2014; Dicke et al., 2017; Skaalvik \& Skaalvik, 2018), which involves, on the one hand, considering the demands of the workplace, such as, the physical and psychological efforts and costs to be provided by the employee. When these demands are too high, they are generally associated with a decrease in employees' mental health, which can lead to exhaustion or other negative effects (Bakker \& Demerouti, 2014; Dicke et al., 2017; Skaalvik \& Skaalvik, 2018). On the other hand, this model considers the resources required to achieve professional goals, reducing the consequences of work demands and allowing the worker to develop and learn. These resources, often of a professional nature, are associated with increased employee engagement and satisfaction (Bakker \& Demerouti, 2014; Dicke et al., 2017; Skaalvik \& Skaalvik, 2018). Thus, professional resources mitigate the negative impact of work requirements on employees' wellbeing and commitment (Skaalvik \& Skaalvik, 2018). Applied to early childhood educators in the context of the pandemic, this model provides an understanding of how the new work demands, both in terms of challenges and professional resources associated with the situation, can involve greater physical and mental efforts (see Fig. 1). This theoretical model will support data analysis regarding the tasks carried out by early childhood educators in relation to parents, as well as the new activities carried out during the remote work periods and 


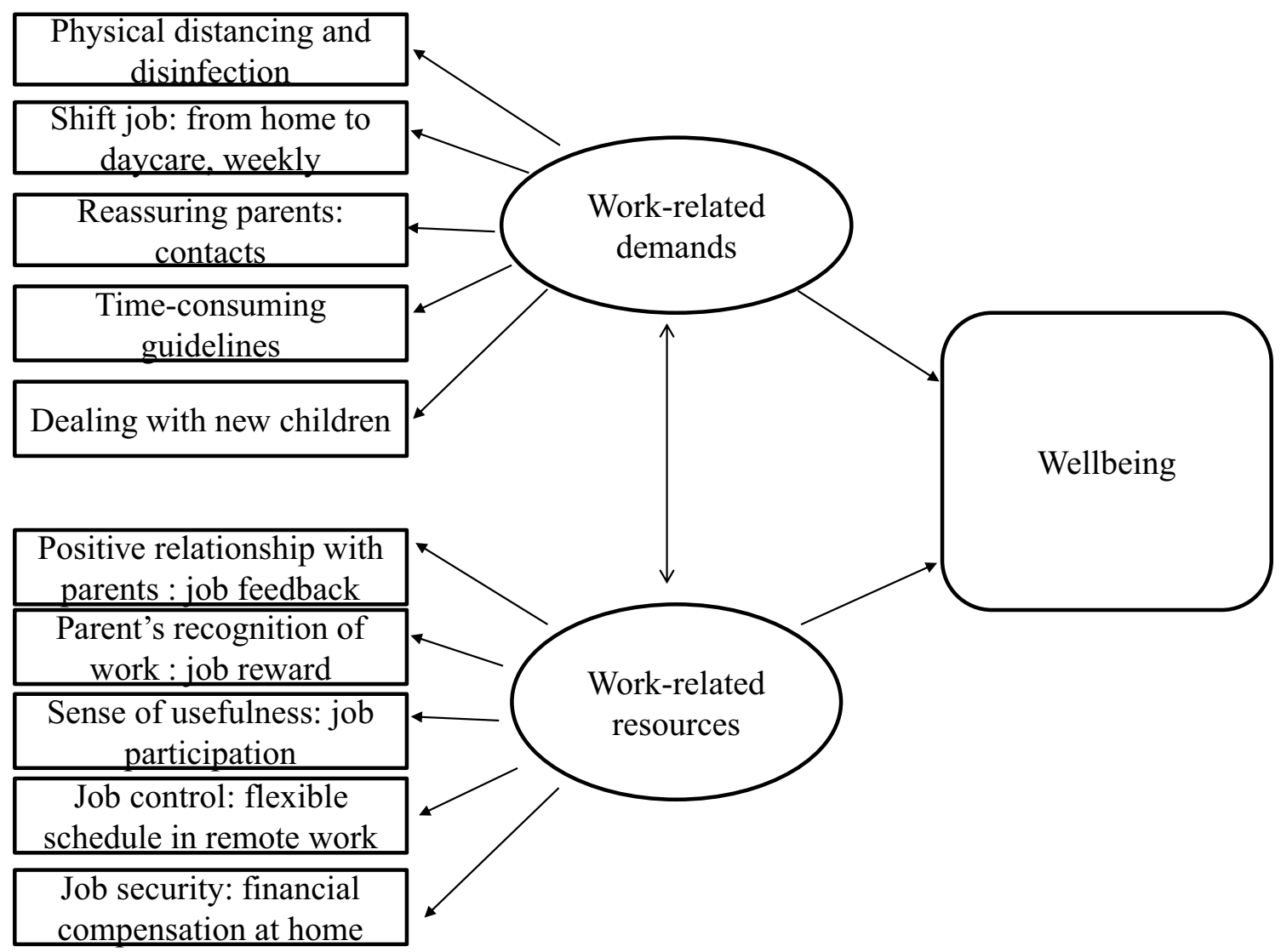

Fig. 1 The job demands and resources model for early childhood educator in pandemic

their learning in this context. To our knowledge, very few studies have documented the consequences of the pandemic on the emotional state of ECEC educators as well as on the working conditions in both ECEC services and remote work. along with the learning resulting from it, as related to the novel problems caused by COVID- 19 .

\section{Objectives}

The purpose of this study was to document early childhood educators' perceptions of their emotional state, their relationships with parents, and their learning in new professional activities, both in the early childhood education and care (ECEC) work environment and during remote work, during the period of emergency care services in April 2020.

\section{Method}

\section{Research Design}

This descriptive study was developed in collaboration with a regional ECEC association, a non-profit organization dedicated to supporting and defending the ECEC centres in the region, and providing professional development services while representing them in various regional and national jurisdictions. This regional association with whom the first author was already collaborating, contacted her at the very beginning of the confinement to support the educational teams as they adapted to the measures put in place during the ECS. Following virtual meetings with ECEC managers (April 2020), a virtual survey to document early childhood educators' perceptions of the effects of this emergency work environment on emotional awareness, their relationships with parents, and new learning for work and remote work was undertaken. An initial version of the survey was developed in May 2020 and then revised by professionals from the regional ECEC association before creating a new version that could be pre-tested with a dozen potential respondents and adjusted minimally to clarify certain issues.

\section{Recruitment and Procedures}

The recruitment of participants was carried out in Monteregie (Quebec, Canada) in May 2020. The 98 ECEC managers who are members of the regional ECEC association received an email from their association inviting them to forward a confidential online survey (95 questions) to their 
early childhood educators. The cumulative data on the Survey Monkey app were then forwarded to the first author in order to carry out statistical analyses (with the SPSS software, 26th version). The target population consisted of approximately 2500 early childhood educators, located in 67 municipalities (Institut de la Statistique du Québec [ISQ] 2020).

\section{Sample}

The convenience sample consisted of 372 early childhood educators from 40 municipalities in Monteregie, the second-largest region in the province of Quebec (Canada). This sample appears to have a distribution similar to the target population of the regional ECEC association's members. Respondents were between the ages of 18 and 61 and almost two-thirds (61.3\%) of them were between 31 and 50 years of age, a higher distribution to that of Quebec's general population (42\%) (Statistics Canada, 2020). Regarding the years of service accumulated in their current childcare service, one-third (33.1\%) of participants indicated having fewer than 5 years of work experience, and participants were far less likely to have 6 to 10 years (14.5\%), of experience. Almost one-third of participants had accumulated 11 to 20 years (35.5\%) of experience, while $16.9 \%$ had accumulated more than 20 years of service. Our data appear to be above the provincial average for early childhood educators with less than 4 years of experience $(16.30 \%)$, and below for those cumulating between 4 and 10 years of experience (31.0\%), and also for those with between 11 and 20 years of experience $(39.0 \%)$ (MF, 2016).

In terms of staff qualifications, a vast majority of respondents $(84.2 \%)$ were considered qualified according to Quebec's MF, i.e., they completed a 3-year post-secondary college program leading to a diploma (33.6\% of participants), a 1-year post-secondary college attestation program (46\% participants), or a 30-credit university certificate, combined with three years of work experience (4.6\% of participants). Only $12.3 \%$ were considered unqualified, while $3.5 \%$ had another degree. These proportions of ECEC-qualified personnel are similar to those observed by the MF (2016) for all early childhood educators in Quebec (84.9\%). In addition, two-thirds of respondents $(62.5 \%)$ reported having worked 9 to $24 \mathrm{~h}$ per week during this period, while onefifth $(20.1 \%)$ worked less than $8 \mathrm{~h}$ per week, and one-tenth (11.8\%) worked from 25 to $32 \mathrm{~h}$ per week. A very small proportion reported having worked more than $33 \mathrm{~h}$ per week (5.6\%). Finally, very few early childhood educators in the sample $(12.9 \%)$ reported chronic health problems (e.g., diabetes, high blood pressure, heart problems), and only $15.3 \%$ reported living with a relative presenting a health risk (e.g., chronic health problem, pregnant or over 70 years of age) at the time of the survey.

\section{Measures}

The online survey was originally composed of 95 questions, but only 48 questions were retained for this article. Among the 48 questions, there are 20 nominal questions (yes-no), 14 ordinal questions (Likert-type scale), 5 interval questions (demographic), 2 ratio questions (continuous data) and 7 open-ended questions. The 48 questions are divided into five sections: (1) demographic data (11 questions: regional code, age, health, education level and experience, child at home, schedule), (2) ECS work environment and remote work (6 questions about work, current stress levels and evolution of stress levels), (3) relationships with parents (5 questions about parents' and stress levels, ease of communication, facilitators and challenges), (4) remote working activities (23 questions about schedule, weekly working hours, types of activities, and estimation of usefulness regarding each activity, as well as about facilitating and appreciated factors), (5) upcoming reopening phase (3 questions about concerns, facilitators, and ideal conditions).

\section{Analyses}

Quantitative data were analyzed using SPSS software (26th version). Descriptive frequency analyses were conducted on nominal and interval variables, while central trend analyses (average, standard deviation) were conducted on continuous variables (ordinal and ratio). Chi squares tests were also carried out on certain ordinal variables in order to verify their relationships. First, for the two work contexts, ECS work environment and remote work, the proportions of and stress levels were compared. Chi squares were also carried out on wellbeing and stress levels evolutions. We also compared the proportions of remote work activities, their novelty, and estimates of their level of perceived usefulness. Finally, open-ended questions were grouped according to their emerging theme and a frequency analysis was carried out on the identified themes. Since this was a survey that did not require the answer to one question in order to move on to the next, some questions have more missing data (MD) than others. Moreover, higher rates of nonresponse were found for almost all of the study-dependent variables, among participants with lower levels of education, suggesting that those with post-secondary college-level attestation certificates are more likely not to answer questions than others. In addition, there is also more MD for questions about and stress at work, as well as the fluctuation of these and 
stress conditions among participants living with a relative at risk. The rates of these MD are specified in each of the results tables to be considered in the interpretation of the results.

\section{Results}

\section{Work and Remote Work and Stress}

First, it is important to note that remote work activities were carried out on a variable schedule for $73.7 \%$ of early childhood educators over an average of $12.74 \mathrm{~h}(\mathrm{SD}=8.32 \mathrm{~h})$ of remote

Table 1 Comparison of workplace well-being and stress levels in emergency childcare services (ECS) work environment and remote work

\begin{tabular}{|c|c|c|c|c|c|}
\hline & \multicolumn{2}{|l|}{ ECS } & \multicolumn{2}{|c|}{ Remote work } & \multirow[t]{2}{*}{$\chi^{2(4)}$} \\
\hline & $\mathrm{n}$ & $\%$ & $\mathrm{n}$ & $\%$ & \\
\hline \multicolumn{6}{|l|}{ Well-being } \\
\hline Very low & $30 a$ & 8.7 & $13 \mathrm{a}$ & 5 & \multirow[t]{7}{*}{$23.68 * * *$} \\
\hline Low & $51 b$ & 14.7 & $20 \mathrm{a}$ & 7.8 & \\
\hline Average & $167 a$ & 48.3 & $108 \mathrm{a}$ & 41.9 & \\
\hline High & $84 b$ & 24.3 & $93 a$ & 36.0 & \\
\hline Very high & $14 b$ & 4.0 & $24 \mathrm{a}$ & 9.3 & \\
\hline Total & 346 & 100 & 258 & 100 & \\
\hline MD & 26 & 6.9 & 114 & 30.6 & \\
\hline \multicolumn{6}{|l|}{ Stress level } \\
\hline Very low & $11 \mathrm{~b}$ & 3.20 & $58 \mathrm{a}$ & 22.60 & \multirow[t]{7}{*}{$100.41^{* * *}$} \\
\hline Low & $57 b$ & 16.50 & $86 a$ & 33.50 & \\
\hline Average & $125 \mathrm{a}$ & 36.10 & $75 a$ & 29.20 & \\
\hline High & $114 b$ & 32.90 & $31 \mathrm{a}$ & 12.10 & \\
\hline Very high & $39 b$ & 11.30 & $7 \mathrm{a}$ & 2.70 & \\
\hline Total & 346 & 100.00 & 257 & 100.00 & \\
\hline MD & 26 & 6.90 & 115 & 30.91 & \\
\hline
\end{tabular}

Note Different letters on the same line represent significant differences

$* * * p=0.0001$ work per week. In addition, a very small proportion of respondents $(6.5 \%)$ did not work at all, neither in a ECS nor in remote work. Finally, just over half of participants (57.6\%) reported having one or more children at home while in remote work.

The first section of the Table 1 compares levels of wellbeing in ECS work environments and in the context of remote work. It is interesting to note that a higher proportion of participants reported low levels of wellbeing in the ECS work environment (14.7\%) compared to remote work (7.8\%). Conversely, participants were more likely to report high levels of wellbeing in the context of remote work (36\%) vs. ECS (24.3\%). The same is true for very high levels of well-being, which is more common in the context of remote work (9.3\%) than in the ECS $(4 \%)\left(\chi^{2(4)}=23.68, p=0.000\right)$.

Table 1 also shows similar trends in analyzing differences in stress levels by work environment $\left(\chi^{2(4)}=109.41\right.$, $p=0.000)$. Participants reported a higher proportion of very low and low levels of stress in the context of remote work (22.6\% and 33.5\%, respectively) than in the one of ECS (3.2\% and $16.5 \%$ respectively). Conversely, a larger proportion of early childhood educators perceived high $(32.9 \%)$ and very high $(11.3 \%)$ levels of stress in the ECS work environment, while fewer reported high (12.1\%) or very high $(2.7 \%)$ levels of stress in the remote work context. Only the proportions of average stress levels do not seem to differ between the two contexts (36.1\% at work in ECS vs. $29.2 \%$ in remote work).

Regarding the evolution of emotional states in the context of ECS work environment between the beginning and the end of April (Table 2), the comparison of proportions indicates that they do not differ significantly $\left(\chi^{2(2)}=2,394\right.$, $p=0.318$ ), suggesting a significant increase in stress levels $(50.3 \%)$ as well as a similar decrease in levels of wellbeing $(55.9 \%)$ in the ECS's work environment during the month of April.

\section{Relationships with Parents}

Early childhood educators also provided estimates of all parents in their group regarding their levels of wellbeing. It should be noted that very few early childhood educators
Table 2 Fluctuating levels of well-being and stress in the emergency childcare services environment in April

\begin{tabular}{|c|c|c|c|c|c|c|c|}
\hline & \multicolumn{2}{|c|}{$\begin{array}{l}\text { Fluctuation of well-being } \\
\text { levels }\end{array}$} & & \multicolumn{2}{|l|}{$\begin{array}{l}\text { Fluctuation of } \\
\text { stress levels }\end{array}$} & \multirow[t]{2}{*}{$\chi^{2(2)}$} & \multirow[t]{2}{*}{$p$} \\
\hline & $n$ & $\%$ & & $n$ & $\%$ & & \\
\hline Decrease & $193 a$ & 55.9 & Increase & $174 a$ & 50.3 & 2.294 & 0.318 \\
\hline Unchanged & $81 \mathrm{a}$ & 23.5 & Unchanged & $89 a$ & 25.7 & & \\
\hline Increase & $71 \mathrm{a}$ & 20.6 & Decrease & $83 a$ & 24.0 & & \\
\hline Total & 345 & 100.0 & Total & 346 & 100.0 & & \\
\hline DM & 27 & 6.9 & & 26 & 7.2 & & \\
\hline
\end{tabular}

Note Different letters on the same line represent significant differences 
perceived that parents experienced very low and low levels of wellbeing $(4.23 \%)$, while $32.3 \%$ perceived average levels of wellbeing and more than one-third (37.7\%) perceived that parents felt high and very high levels of wellbeing. It should be noted that $25.4 \%$ of respondents had no contact with parents in April.

On the other hand, when estimating parent stress levels, just over a quarter of early childhood educators (26.6\%) felt that parents had very low and low levels of stress, while just over half $(56.6 \%)$ perceived average stress levels, and less than one-fifth (16.8\%) indicated they felt that parents demonstrated high and very high stress levels.

Despite these perceptions, results also indicated that more than half (57\%) of ECS early childhood educators rated their interactions with parents as easy or very easy, while a quarter (26.4\%) considered these interactions moderately easy and $16.8 \%$ felt that these interactions were difficult or very difficult to conduct.

When asked about the factors that facilitated or hindered these interactions, the participating early childhood educators named several items (Table 3). Among the five factors most frequently cited as facilitating their interactions with parents was the possibility of having direct contact with parents (12.62\%), as well as having more time to interact with them $(12.15 \%)$. The early childhood educators also spoke of the recognition of their work expressed by parents (11.68\%), the short duration of the interactions $(9.81 \%)$, and the reduction of back and forth movement within the ECS interactions (8.41\%).

Conversely, the five factors that hindered interaction with parents most frequently expressed by educators were communication challenges (26.6\%), the fact that parents could not enter the ECS $(23.87 \%)$, the fact that some parents were unknown to them as they were essential workers (16.87\%), and the need to integrate new children (8.11\%). In addition, a small proportion of early childhood educators expressed that there were no barriers to their relationships with parents (7.21\%).

\section{Remote Work}

For early childhood educators' remote work activities, Table 4 compares the frequency of seven types of activities performed. It also includes the proportion of those that were done for the first time or had rarely been performed before, as well as the level of agreement among educators as to their sense of usefulness in carrying out each of the activities. First, when comparing the proportion of participants who completed each of these activities, it can be noted that online training activities $(96.3 \%)$ and professional readings (96\%) were the most frequently done in remote work. Furthermore, telephone calls to children and their confined parents $(50.9 \%)$, virtual encounters with co-workers (48.3\%), and the creation of video capsules for children of their group $(41.1 \%)$ followed in terms of frequencies. Finally, it is noted that live virtual encounters with children $(21.8 \%)$ and the creation of video capsules for parents (17.2\%) were the least frequently mentioned remote work activities.

When comparing the proportions of these activities that were performed for the first time or that had rarely been performed by participants, there are four activities with similar frequencies: the creation of video capsules for parents (97.8\%) and for children (96.4\%), and virtual encounters with colleagues (94.7\%) and with children (96.4\%). Phone calls to children and parents $(75.2 \%)$ came second, while online training activities $(58.8 \%)$ came in third place. The least performed activity reported was professional reading (15.1\%). Also, the early childhood educators expressed their perceived sense of usefulness for each of these remote work activities. Chi square analyses indicate that educators were significantly less likely to have agreed that professional readings made them feel useful (64.9\%). They were significantly more likely to have reported that virtual encounters with children (93\%) and phone calls to parents (83.9\%) made them feel useful. Conversely, the Chi square analyses indicated that significantly fewer participants agreed that the
Table 3 Factors facilitating or hindering interactions with parents

\begin{tabular}{|c|c|c|c|c|c|}
\hline Facilitating & $\mathrm{n}$ & $\%$ & Hindering & $\mathrm{n}$ & $\%$ \\
\hline Direct contact & 27 & 12.62 & Communication challenges & 58 & 26.13 \\
\hline More time to exchange & 26 & 12.15 & Parents could not enter the ECS & 53 & 23.87 \\
\hline Recognition of their work & 25 & 11.68 & Unknown parents & 36 & 16.22 \\
\hline Short duration of interactions & 21 & 9.81 & Integration of new children & 18 & 8.11 \\
\hline Reduction of movement within the CPE & 18 & 8.41 & None & 16 & 7.21 \\
\hline Welcoming attitude & 17 & 7.94 & Other responses ${ }^{\mathrm{a}}$ & 41 & 18.47 \\
\hline None & 11 & 5.14 & & & \\
\hline Other responses ${ }^{\mathrm{a}}$ & 69 & 32.24 & & & \\
\hline Total & 214 & 100.00 & Total & 222 & 100.00 \\
\hline MD & 158 & 42.40 & MD & 150 & 40.32 \\
\hline
\end{tabular}

${ }^{\text {a }}$ The other responses are the accumulation of response categories of less than $5 \%$ frequency each 
Table 4 Activities performed in remote work and perception of usefulness

\begin{tabular}{|c|c|c|c|c|c|c|c|c|c|c|c|}
\hline & & \multicolumn{3}{|c|}{ I've done it } & \multicolumn{3}{|c|}{ First time/rare } & \multicolumn{4}{|c|}{ Sense of usefulness } \\
\hline & & Yes & No & Total & Yes & No & Total & Agree & Neutral & Disagree & Total \\
\hline \multirow[t]{3}{*}{ Video capsule creation for children } & $\mathrm{n}$ & $113 \mathrm{a}$ & $162 \mathrm{a}$ & 275 & $107 \mathrm{a}$ & $4 a$ & 111 & $86 a, b$ & $13 \mathrm{a}$ & $11 \mathrm{a}, \mathrm{b}$ & 110 \\
\hline & $\%$ & 41.1 & 58.9 & 100 & 96.4 & 3.6 & 100 & 78.2 & 11.8 & 10 & 100 \\
\hline & MD & 97 & $26.08 \%$ & & 261 & $70.26 \%$ & & 262 & & $70.43 \%$ & \\
\hline \multirow[t]{3}{*}{ Video capsule creation for parents } & $\mathrm{n}$ & $47 \mathrm{~b}$ & $226 b$ & 273 & $45 \mathrm{a}$ & $1 \mathrm{a}$ & 46 & $16 \mathrm{c}$ & 20 & $10 \mathrm{~b}$ & 46 \\
\hline & $\%$ & 82.8 & 17.2 & 100 & 97.8 & 2.2 & 100 & 34.8 & 43.5 & 217 & 100 \\
\hline & MD & 99 & $26.61 \%$ & & 326 & $87.63 \%$ & & 326 & & $87.63 \%$ & \\
\hline \multirow[t]{3}{*}{ Professional readings } & $\mathrm{n}$ & $261 \mathrm{c}$ & $11 \mathrm{c}$ & 272 & $39 b$ & $220 b$ & 259 & $168 b$ & $68 \mathrm{~b}$ & $23 a, b$ & 259 \\
\hline & $\%$ & 96 & 4 & 100 & 15.1 & 84.9 & 100 & 64.9 & 26.3 & 8.9 & 100 \\
\hline & MD & 100 & $26.88 \%$ & & 113 & $30.38 \%$ & & 113 & & $30.38 \%$ & \\
\hline \multirow[t]{3}{*}{ Online training } & $\mathrm{n}$ & $260 \mathrm{c}$ & $10 \mathrm{c}$ & 270 & $153 c$ & $107 \mathrm{c}$ & 260 & 196a,b & $42 \mathrm{a}, \mathrm{b}$ & $21 \mathrm{a}, \mathrm{b}$ & 259 \\
\hline & $\%$ & 96.3 & 3.7 & 100 & 58.8 & 41.2 & 100 & 75.7 & 16.2 & 8.1 & 100 \\
\hline & $\mathrm{MD}$ & 102 & $27.42 \%$ & & 112 & $30.11 \%$ & & 113 & & $30.37 \%$ & \\
\hline \multirow[t]{3}{*}{ Live virtual encounters with children } & $\mathrm{n}$ & $58 \mathrm{~b}$ & $208 b$ & 266 & $54 \mathrm{a}$ & $2 \mathrm{a}$ & 57 & 53 & 4 & 0 & 57 \\
\hline & $\%$ & 21.8 & 78.2 & 100 & 96.4 & 3.6 & 100 & 93.0 & 7 & 0 & 100 \\
\hline & MD & 106 & $28.49 \%$ & & 315 & $84.68 \%$ & & 315 & & $84.68 \%$ & \\
\hline \multirow[t]{3}{*}{ Live virtual encounters with co-workers } & $\mathrm{n}$ & $128 \mathrm{a}$ & $137 \mathrm{a}$ & 265 & $118 \mathrm{a}$ & $9 \mathrm{a}$ & 127 & $95 \mathrm{a}, \mathrm{b}$ & 23 & 9 & 127 \\
\hline & $\%$ & 48.3 & 51.7 & 100 & 94.7 & 5.3 & 100 & 74.8 & 18.1 & 7.1 & 100 \\
\hline & MD & 107 & $28.76 \%$ & & 245 & $65.86 \%$ & & 245 & & $65.86 \%$ & \\
\hline \multirow[t]{3}{*}{ Calls to children and confined parents } & $\mathrm{n}$ & $135 a$ & $130 \mathrm{a}$ & 265 & $103 d$ & $34 d$ & 137 & $115 a$ & $15 \mathrm{a}$ & $7 \mathrm{a}$ & 137 \\
\hline & $\%$ & 50.9 & 49.1 & 100 & 75.2 & 24.8 & 100 & 83.9 & 10.9 & 5.1 & 100 \\
\hline & MD & 107 & $28.76 \%$ & & 235 & $63.17 \%$ & & 235 & & $63.17 \%$ & \\
\hline$\chi^{2(6)}$ & \multicolumn{4}{|c|}{$667.57 * *$} & \multicolumn{3}{|l|}{$414.55^{* *}$} & \multicolumn{4}{|l|}{$70.44 * *$} \\
\hline
\end{tabular}

Different letters on the same line represent significant differences

$* * p=0,01$ and $* * * p=0,001$

creation of video capsules for parents made them feel useful (34.8\%).

Finally, with respect to the appreciated aspects of remote work, Table 5 highlights several of them. Of those most frequently mentioned, more than one-third of respondents reported being able to work at their own pace $(34.7 \%)$, and almost one quarter $(21.92 \%)$ reported appreciating the opportunity to do engage in professional learning activities, $10.96 \%$ reported appreciating being able to work in the comfort of their own homes, while others added that they appreciated the opportunity to get work done $(7.76 \%)$ or to deal with fewer disruptions $(5.96 \%)$.
Table 5 The most and least appreciated aspects of remote work

\begin{tabular}{|c|c|c|c|c|c|}
\hline Most appreciated & $\mathrm{n}$ & $\%$ & Least appreciated & $\mathrm{n}$ & $\%$ \\
\hline Work at their own pace & 76 & 34.70 & Work-family balance & 32 & 14.68 \\
\hline Professional learning activities & 48 & 21.92 & None & 30 & 13.76 \\
\hline In the comfort of their home & 24 & 10.96 & Professional learning activities & 27 & 12.38 \\
\hline Advance their task & 17 & 7.76 & Stress/anxiety & 22 & 10.09 \\
\hline Fewer disruptions & 13 & 5.94 & Technological difficulties & 14 & 6.42 \\
\hline \multirow[t]{5}{*}{ Other responses $^{\mathrm{a}}$} & 41 & 18.72 & Solitude & 14 & 6.42 \\
\hline & & & Unclear task or schedule & 13 & 5.96 \\
\hline & & & Workload & 12 & 5.50 \\
\hline & & & Lack of contact with co-workers & 12 & 5.50 \\
\hline & & & Other responses $^{\mathrm{a}}$ & 42 & 19.26 \\
\hline Total & 219 & 100.00 & Total & 218 & 100.00 \\
\hline MD & 153 & 41.111 & MD & 154 & 41.39 \\
\hline
\end{tabular}

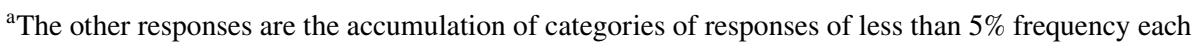


In terms of less appreciated aspects of remote work, while $13.76 \%$ of participants did not see any, $14.68 \%$ identified difficulties with work-family balance and $12.38 \%$ said they did not enjoy professional learning. One-tenth of participants $(10.09 \%)$ felt stress or anxiety in the pandemic context, while a smaller proportion (6.42\%) referred to technological difficulties as one of the less appreciated aspects of remote work.

\section{Upcoming Reopening Phase}

In closing, the results also capture the early childhood educators' level of concern about the upcoming deconfinement, that is, the period of gradual reopening of childcare to all children in the regular clientele that took place from midMay. It was noted that less than $10 \%$ of participants were not at all concerned $(8.7 \%$ ), while $29.6 \%$ were moderately worried and that $41.1 \%$ said they were very worried or extremely worried about this upcoming deconfinement.

Finally, educators were asked about the challenges they foresaw regarding the future deconfinement, as well as to identify conditions put in place during the period of ECS that they would like to see maintained. Table 6 outlines the themes most frequently mentioned by respondents. The most important challenge for nearly $40 \%$ of them was for children and adults to respect physical distancing, while a smaller proportion (12.41\%) identified the new requirement to wear personal protective equipment (mask, visor or protective glasses), and one-tenth (10.99\%) mentioned the challenge of maintaining all health measures with a full group of children, followed by the requirement to carry out disinfection regularly (6.74\%). A smaller proportion identified having to accompany some of their colleagues who were stressed in the face of this deconfinement as a challenge (5.32\%).

With regards to working conditions during the period of ECS that early childhood educators would like to maintain, almost one-third stressed the importance of the low ratio (28.84\%), while one-tenth found that frequent disinfection of equipment and the environment (11.98\%) or compliance with health guidelines (10.11\%) should be preserved. It should be noted that this disinfection had to be done twice a day whereas in a normal period (without a pandemic), this operation is done once a day or weekly depending on the type of equipment or surface (MFA, 2008). Finally, fewer than ten percent of respondents indicated the possibility of remote work $(9.74 \%)$ and fewer than five percent mentioned opportunities for staff communication with parents (4.12\%).

\section{Discussion}

In April 2020, Quebec's early childhood educators experienced many challenges and had to adapt to the health crisis. The data from this study suggests a significant deterioration in emotional state, both in terms of wellbeing and stress at work in the ECS work environment. The results regarding stress levels at work are similar to Quebec data collected in the general population over the same period by the INSPQ (2020), where four out of ten individuals reported experiencing increased levels of worry and anxiety. These results are concerning, but not surprising, given the situation, as the educators had a responsibility to provide quality childcare to children who were also going through a difficult period related to confinement, and who also had to adapt to it. The parents of these children also experienced significant challenges, many of whom were health care or social service workers. The results will be discussed using the theoretical framework to compare educators' workrelated demands and emotional state.

In terms of the challenges of remote work, the results of our study are consistent with those of Hamouche (2020) and Baert et al. (2020), who suggest that stress levels increase when remote work employees have children at home due to schools being closed during the quarantine period. The study's participants identified family-work balance as the least appreciated aspect of remote work during the pandemic, especially for those with children.
Table 6 Challenges and conditions to be maintained during the deconfinement period

\begin{tabular}{|c|c|c|c|c|c|}
\hline Challenges & $\mathrm{n}$ & $\%$ & Conditions to be maintained & $\mathrm{n}$ & $\%$ \\
\hline Physical distancing & 110 & 39.01 & Lower ratio & 77 & 28.84 \\
\hline Personal protective equipment & 35 & 12.41 & Disinfection & 32 & 11.98 \\
\hline Disinfection & 19 & 6.74 & Compliance with health guidelines & 27 & 10.11 \\
\hline Maintaining all health measures & 31 & 10.99 & Remote work possibilities & 26 & 9.74 \\
\hline Colleagues' stress & 15 & 5.32 & Communication & 11 & 4.12 \\
\hline Adaptation & 15 & 5.32 & Other responses ${ }^{\mathrm{a}}$ & 94 & 35.20 \\
\hline Other responses ${ }^{\mathrm{a}}$ & 57 & 20.21 & & & \\
\hline Total & 282 & 100 & Total & 267 & 100 \\
\hline MD & 90 & 24.10 & MD & 105 & 28.22 \\
\hline
\end{tabular}

${ }^{\mathrm{a}}$ The other responses are the accumulation of categories of responses of less than $5 \%$ frequency each 


\section{Work-Related Demands}

Some of the challenges of working in the ECS and doing remote work that were identified by participants may explain the levels of wellbeing and stress perceived by early childhood educators based on the job demands and resources model (Bakker \& Demerouti, 2014; Dicke et al., 2017). First, it is possible to highlight the higher demands in terms of physical distancing and disinfection of the workplace when early childhood educators were in the ECS with the children. They had to make more physical and psychological efforts, compared to their usual work, to welcome and reassure new children and their parents who had to work in very difficult conditions (only essential workers were admitted), while making sure to comply with the new complex and time-consuming health guidelines. It is therefore possible that these new ECS work requirements in the context of a pandemic appeared to be too high by a majority of the respondents, leading to a decline in work wellbeing in the ECS that was observed in more than half of the respondents, and a consequent increase in the level of stress at work (Bakker \& Demerouti, 2014; Dicke et al., 2017).

\section{Work-Related Resources}

According to the job demands and resources model, the presence of professional resources is associated with increased employee engagement and satisfaction (Bakker \& Demerouti, 2014; Dicke et al., 2017; Skaalvik \& Skaalvik, 2018). Relationships with parents (essential workers) appears to be a resource that enabled educators to achieve their professional goals with children. In particular, the emotional state of these parents, the quality of the interactions with them during this period, the opportunities for direct contact with them, and the parents' recognition of their work seem to have contributed to their perception of the ease of interactions, despite the context of the pandemic.

Similarly, in the context of remote work, the sense of usefulness associated with carrying out remote activities that allowed them to maintain a relationship with children and parents (e.g., creation of video capsules for children, phone calls to parents) could act as a resource, allowing early childhood educators to feel a higher level of wellbeing in the context of remote work. Indeed, when the educators had to perform many new activities during remote work periods, they reported lower levels of stress and higher levels of wellbeing in this context than in the context of working in the ECS. It is conceivable that the flexibility associated with the remote work environment (Johnson et al., 2020) has been able to increase educator resources and thus contribute to higher levels of wellbeing and lower levels of stress in the context of remote work. Especially since the aspects of remote work that were most appreciated by the early childhood educators in this study concern precisely the possibility of going at their own pace and whether or not they have children at home, the concept of having some control over the situation and flexibility, as mentioned by Johnson et al. (2020) among the advantages of remote work, may be important resources for educators in this context.

\section{Resources to Compensate for Work Demands}

Another hypothesis to explain the higher levels of wellbeing and the lower levels of stress in remote work compared to the ECS work environment would be the resources available to compensate for work demands. Thus, it is very likely that continuing to receive their wages in remote work situations helped to mitigate the negative consequences of the ECS work demands and to provide a higher level of wellbeing while working remotely (Skaalvik \& Skaalvik, 2018). Indeed, having the opportunity to perform remote work activities for most of their work week while continuing to be paid at their usual salary level, may have offset not only the pressure associated with the challenges related to the novelty of activities, but also the disadvantages connected to remote work in the scientific literature. It should be noted that the Quebec government is the only province in Canada who chose to pay early childhood educators to work remotely despite the low rate of children attending ECS. This highlights inequalities among early childhood educators across Canada and other countries. Here we see the benefits for early childhood professionals of a public early childhood education system, described as more "competent" by Urban et al. (2012), i.e., emphasizing adequate economic investments as well as working conditions and similar qualification for the entire education system. This type of system is also based on public and legislated funding in Quebec, which is not yet the case in the rest of Canada (Friendly et al., 2020) or in many other ECEC models around the world.

For the deconfinement coming in the near future, the job demands and resources model (Bakker \& Demerouti, 2014; Dicke et al., 2017) also helps to explain early childhood educators' levels of concern about this new phase of the pandemic. When this survey was completed, educators were preparing for the gradual return of children from their regular group, as ECS were to cease within 2 weeks. Moreover, the announcement of new health guidelines for this upcoming deconfinement period seemed to cause concern among ECEC educators who learned that although they had never had to wear a disposable mask or visor and protective glasses during the ECS period, they would now have to do so while enforcing the two-meter physical distancing rule between the children, between adults and children, and between adults during the deconfinement. This two-meter rule was then eased during the summer for children. Nevertheless, when completing this survey, it is likely that a certain level 
of anticipatory anxiety coupled with the prospect of low levels of professional support to face these challenges can partly explain the high levels of worry that were prevalent regarding the upcoming deconfinement. However, it is possible to identify several conditions of the ECS mentioned by the educators as potential resources that contributed to their positive emotional state at the time of the deconfinement. For example, the introduction of a lower adult-to-child ratio was seen as a facilitator for early childhood educators to help them gradually adapt to the multiple health requirements. The lower ratio being a structural variable associated with several dimensions of quality (Bigras et al., 2020), it is reasonable to believe that the latter could be considered a facilitating factor for educators' emotional state regarding the deconfinement. Further comparative studies about structural differences between ECEC models in the pandemic context could be interesting to sustain this hypothesis.

\section{Limitations of the Study}

This study has several limitations. First, because this study was conducted in only one region of Quebec, Monteregie, we cannot claim the representativeness of our sample to all of Quebec. It is also difficult to say that our sample is representative of the Monteregie early childhood educator characteristics. Thus, although the proportion of qualified staff among our participants is similar to that of official Quebec data, the proportion of years of service appears to be different. Furthermore, these results do not illustrate the views of educators in other Quebec ECEC systems, including family day care and subsidized and unsubsidized private childcare, who were not included in the survey, as few provided ECS during the confinement period. In addition, the administered survey was developed quickly based on community-identified needs. The time allotted did not make it possible to develop a questionnaire for which its psychometric properties were proven. However, the survey allowed for data collection at the peak of the pandemic and provided a certain "base level" to then design a professional development service using recognized instruments. To follow up, it may be appropriate to conduct a longitudinal population-level study measuring the impact of the pandemic on the change of early childhood educators' emotional states. Such an online study, using standardized questionnaires at regular intervals, measuring levels of wellbeing, stress, and burnout, as well as depressive symptoms, could be used to monitor the mental health status of early childhood educators and ultimately identify ways to implement supports tailored to their needs.

Also, this type of survey, although distributed online and in no way able to identify participants (Butori \& Parguel, 2010) is, however, sensitive to nonresponse biases (Denscombe, 2009). Nevertheless, we made the decision that survey participants may refrain from answering questions. While this strategy is ethically justifiable given the state of stress that was experienced in ECEC settings and our reluctance to put additional pressure on early childhood educators, this results in high rates of missing data for certain questions, increasing the potential for the presence of a non-equivalence of respondents' bias based on rates of nonresponse (Dale, 2006). For example, some of the questions in this study, such as the sense of usefulness associated with some remote work activities, have a particularly high rate of non-response. Nevertheless, as Dale (2006) suggests, if the non-responses come from a particularly homogeneous sample, this appears to be less problematic than if they come from a heterogeneous sample. In the case of our sample, analysis of nonrespondent's characteristics suggests that participants with a post-secondary attestation certificate level of education did not answer several questions. It can therefore be assumed that our study is less representative of their reality. Finally, the variable response format of the questionnaire may be another reason why respondents did not answer all of the questions, as there may have been too many instructions to read in order to understand how to respond to the different questions.

\section{Conclusion}

In conclusion, the results of the study highlight areas to be consolidated and avenues to explore. They are particularly relevant for ECEC services or settings in other parts of the world that will have to support and work with these professionals in the coming months, while the health crisis continues. Furthermore, public health directors, policy-makers, and childcare networks will be able to draw on implications to support early childhood professionals to improve their emotional state at work. In fact, the current situation has changed significantly since the reopening of childcare services in Quebec, as elsewhere. Indeed, since summer 2020, changes have become the norm in ECEC services. Educational staff must regularly adapt their practices in response to the new operating rules imposed by public health in order to adapt to the changing pandemic. This pressure to adapt is likely to have long-term negative effects on the wellbeing and emotional state of educational staff. There is an urgent need for more research that monitors those aspects in order to put forward strategies to promote educator wellbeing and mental health.

However, this study notes that some positive aspects of ECS work combined with remote work appear to have more potential to contribute to the resources of early childcare educators during this period of uncertainty. One way to increase the level of wellbeing at work in the CPE would be to offer educators the opportunity to perform activities 
similar to those identified in this study, because of the sense of usefulness and control that they provided. Moreover, beyond working conditions coupled with appropriate remuneration, the literature suggests that wellbeing at work also depends on the existence of healing and support activities tailored to individual needs (Dicke et al., 2017). From this perspective, the provision of professional resources, such as social support and opportunities for peer contact in a positive organizational climate, opportunities for self-reliance at work, innovation, and professional development would be among the positive resources that would promote wellbeing at work while reducing negative impacts. Other ways to increase early childhood educators' level of wellbeing at work in the current pandemic context include providing opportunities to reflect as a team on educational projects and to express themselves about the challenges of the pandemic. In addition, opportunities to engage in self-care activities so that they are able to focus on children's needs are recommended (Dicke et al., 2017).

In closing, there is no doubt that the situation remains difficult and that additional financial resources are still needed to overcome the constraints of the continuing pandemic. However, it is urgent to recognize that young children's health, safety, and quality of life, as well as that of their families, are dependent on the wellbeing of early childhood educators during this time of uncertainty. Indeed, this pandemic reveals the complexity, but also the essential nature of the work of early childhood educators, in particular, by identifying their needs for support and recognition essential to their professional commitment. It is possible to take advantage of this crisis to create and improve publicly funded childcare systems. As Urban and his colleagues point out in their article titled It Takes More Than a Village (2018) "A competent system requires coordinated approaches to governance, resourcing, professional preparation, and evaluation that embrace complexity" (Urban et al. 2012, p. 3). It is by ensuring these conditions that childcare services will survive this pandemic, recover, and develop to better meet the needs of professionals, children, families, and society.

\section{References}

Baert, S., Lippens, L., Moens, E., Sterkens, P., \& Weytjens, J. (2020). The Covid-19 crisis and telework: A research survey on experiences, expectations and hopes. IZA Discussion Paper, 13229, 1-37. Retrieved from https://papers.ssrn.com/sol3/papers.cfm? abstract id $=3596696$

Bakker, A. B., \& Demerouti, E. (2014). Job demands-resources theory. Wellbeing, 3(2), 1-28. https://doi.org/10.1002/9781118539415. wbwell019

Bigras, N., Dessus, P., Lemay, L., Bouchard, C., \& Lequette, C. (2020). Qualité de l'accueil d'enfants de 3 ans en centres de la petite enfance au Québec et en maternelles en France.
Enfance-Famille-Génération, 35. Retrieved from https://journ als.openedition.org/efg/10581

Blouin-Genest, G., Carignan, M.-È., Champagne-Poirier, O., David, M. D., Généreux, M., \& Roy, M. (2020). Enquête de l'université de Sherbrooke sur les impacts psychosociaux de la pandémie - L'anxiété et la dépression : une deuxième catastrophe au Québec. Université de Sherbrooke. Retrieved from https://www.usherbrooke.ca/actualites/nouvelles/nouvellesdetails/article/43540/

Burman, R., \& Goswami, T. G. (2018). A systematic literature review of work stress. International Journal of Management Studies, 5(3-9), 112-132. https://doi.org/10.18843/ijms/v5i3(9)/15

Butori, R., \& Parguel, B. (2010). Les biais de réponse - Impact du mode de collecte des données et de l'attractivité de l'enquêteur. AFM, 2010, France. Retrieved from https://halshs.archives-ouvertes.fr/ file/index/docid/636228/filename/AFM_2010_Version_DA_finit ive_Raph_28_FA_vrier.pdf

Cantin, G., \& Morache, C. (2015). Trousse partenariat: des outils pour l'enseignement de la compétence à établir une relation de partenariat avec les parents en éducation à l'enfance. Université du Québec.

Corr, L., Davis, E., LaMontagne, A. D., Waters, E., \& Steele, E. (2014). Childcare providers' mental health: a systematic review of its prevalence, determinants and relationship to care quality. International Journal of Mental Health Promotion, 16(4), 231-263. https://doi.org/10.1080/14623730.2014.931067

Cumming, T., \& Wong, S. (2019). Towards a holistic conceptualisation of early childhood educators' work-related well-being. Contemporary Issues in Early Childhood, 20(3), 265-281. https://doi.org/ $10.1177 / 1463949118772573$

Curbow, B., Spratt, K., Ungaretti, A., McDonnell, K., \& Breckler, S. (2000). Development of the child care worker job stress inventory. Early Childhood Research Quarterly, 15, 515-536. https://doi.org/ 10.1016/S0885-2006(01)00068-0

Dale, A. (2006). Quality issues with survey research. International Journal of Social Research Methodology, 9(2), 143-158. https:// doi.org/10.1080/13645570600595330

Del Boca, D., Oggero, N., Profeta, P., \& Rossi, M. (2020). Women's and men's work, housework and childcare, before and during COVID-19. Review of Economics of the Household, 18, 10011007. https://doi.org/10.1007/s11150-020-09502-1

Denscombe, M. (2009). Item non-response rates: a comparison of online and paper questionnaires. International Journal of Social Research Methodology, 12(4), 281-291. https://doi.org/10.1080/ 13645570802054706

Dicke, T., Stebner, F., Linninger, C., Kunter, M., \& Leutner, D. (2017). A longitudinal study of teachers' occupational well-being: Applying the job demands-resources model. Journal of Occupational Health Psychology, 23(2), 262-277. https://doi.org/10.1037/ocp00 00070

Friendly, M., Forer, B., \& Vickerson, R. (2020). La pandémie a créé un avenir incertain pour les services de garde à l'enfance au Canada-Faits saillants d'un sondage national. Childcare Resource and Research Unit, Fédération canadienne des services de garde à l'enfance et Un enfant Une place. Retrieved from https://child carecanada.org/sites/default/files/CCprovider-survey-highlightsFR-FINAL.pdf

Gouvernment of Quebec (GQ). (2020a). Décret 177-2020 déclarant l'état d'urgence sanitaire sur tout le territoire québécois. Retrieved from https://cdn-contenu.quebec.ca/cdn-contenu/adm/ $\mathrm{min} /$ sante-services-sociaux/publications-adm/lois-reglements/ decret-177-2020.pdf?1584224223

Gouvernment of Quebec (GQ). (2020b). Services de garde éducatifs à l'enfance dans le contexte de la COVID-19. Gouvernment of Quebec. Retrieved from https://www.quebec.ca/famille-et-souti en-aux-personnes/services-garde-educatifs-enfance-covid19 
Government of Canada. (2020). Canada Emergency Response Benefit (CERB) with CRA. Retrieved from https://www.canada.ca/en/ revenue-agency/services/benefits/apply-for-cerb-with-cra.html

Hall-Kenyon, K. M., Bullough, R. V., MacKay, K. L., \& Marshall, E. E. (2014). Preschool teacher well-being: A review of the literature. Early Childhood Education Journal, 42(3), 153-162. https://doi. org/10.1007/s10643-013-0595-4

Hamouche, S. (2020). COVID-19 and employees' mental health: stressors, moderators and agenda for organizational actions. Emerald Open Research, 2(15), 1-15. https://doi.org/10.35241/emeraldope nres.13550.1

Institut de la Statistique du Québec. (2020). Le bilan démographique du Québec. Éditions 2020. Retrieved from https://statistique.quebec. $\mathrm{ca} / \mathrm{en} /$ fichier/bilan-demographique-du-quebec-edition-2020.pdf

Institut national de santé publique du Québec (INSPQ). (2020). COVID-19: Pandémie, bien-être émotionnel et santé mentale (Données des sondages réalisés du ler avril au 2 septembre 2020). Retrieved from https://www.inspq.qc.ca/sites/default/files/ publications/3083-bien-etre-emotionnel-sante-mentale-COVID19. pdf

Jiang, H. J., Nan, J., Lv, Z. Y., \& Yang, J. (2020). Psychological impacts of the COVID-19 epidemic on Chinese people: Exposure, posttraumatic stress symptom, and emotion regulation. Asian Pacific Journal of Tropical Medicine, 13(6), 252-259. https://doi.org/10. 4103/1995-7645.281614

Johnson, A., Dey, S., Nguyen, H., Groth, M., Joyce, S., Tan, L., et al. (2020). A review and agenda for examining how technologydriven changes at work will impact workplace mental health and employee well-being. Australian Journal of Management, 45(3), 402-424. https://doi.org/10.1177/0312896220922292

Jones, C., Hadley, F., Waniganayake, M., \& Johnstone, M. (2019). Find your tribe! Early childhood educators defining and identifying key factors that support their workplace wellbeing. Australasian Journal of Early Childhood, 44(4), 326-338. https://doi.org/10. 1177/1836939119870906

Leka, S., Griffiths, A., \& Cox, T. (2004). Work organization and stress: Systematic problem approaches for employers, managers and trade union representatives. In Protecting workers' health series, 3. Retrieved from https://apps.who.int/iris/bitstream/handle/ 10665/42625/9241590475.pdf

Ministry of Family (MF). (2020). Questions et réponses concernant la rémunération (COVID). Suivant la réouverture complète et le retour aux ratios à 100\%. Retrieved from https://www.mfa.gouv. qc.ca/fr/publication/Documents/QR-28sept-2020-CPE-GS.pdf

Minsitère de la Famille et des Aînées (MFA). (2008). Aide-mémoire: Nettoyage et désinfection dans un service de garde. Comité de prévention des infections dans les services de garde à l'enfance du Québec. Retrieved from https://www.mfa.gouv.qc.ca/fr/publi cation/Documents/aide-memoire_09-15_PM.pdf

Minsitry of Family (MF). (2016). Situation des centres de la petite enfance, des garderies et de la garde en milieu familial au Québec en 2016. Direction de l'accessibilité et de la qualité des services de garde. Retrieved from https://www.mfa.gouv.qc.ca/fr/publi cation/Documents/situation-sg-2016.pdf

Minsitry of Family (MF). (2019). Accueillir La Petite Enfance. Programme éducatif Pour les services de garde du Québec. Les Publications du Québec. Retrieved from https://www.mfa.gouv.qc.ca/ $\mathrm{fr} /$ publication/Documents/programme_educatif.pdf

Roberts, A. M., Gallagher, K. C., Daro, A. M., Iruka, I. U., \& Sarver, S. L. (2019). Workforce well-being: Personal and workplace contributions to early educators' depression across settings. Journal of Applied Developmental Psychology, 61, 4-12. https://doi.org/ 10.1016/j.appdev.2017.09.007

Rothmann, S. (2008). Job satisfaction, occupational stress, burnout and work engagement as components of work-related wellbeing. $S A$ Journal of Industrial Psychology, 34(3), 11-16.

Ryan, S., \& Whitebrook, M. (2012). More than teachers. In R. Pianta (Ed.), Handbook of early childhood education (pp. 92-106). Guilford Press.

Ryff, C. D., \& Keyes, C. L. M. (1995). The structure of psychological well-being revisited. Journal of personality and social psychology, 69(4), 719-727. https://doi.org/10.1037/0022-3514.69.4.719

Salari, N., Hosseinian-Far, A., Jalali, R., Vaisi-Raygani, A., Rasoulpoor, S., Mohammadi, M., et al. (2020a). Prevalence of stress, anxiety, depression among the general population during the COVID-19 pandemic: a systematic review and meta-analysis. Globalization and Health, 16(1), 1-11. https://doi.org/10.1186/ s12992-020-00589-w

Salari, N., Hosseinian-Far, A., Jalali, R., Vaisi-Raygani, A., Rasoulpoor, S., Mohammadi, M., Rasoulpoor, S., \& Khaledi-Paveh, B. (2020). Prevalence of stress, anxiety, depression among the general population during the COVID-19 pandemic: a systematic review and meta-analysis. Globalization and Health 16, article 57. Retrieved from https://doi.org/10.1186/s12992-020-00589-w

Skaalvik, E. M., \& Skaalvik, S. (2018). Job demands and job resources as predictors of teacher motivation and well-being. Social Psychology of Education, 21(5), 1251-1275. https://doi.org/10.1007/ s11218-018-9464-8

Statistics Canada. (2020). Population estimates on July 1st, by age and sex. Retrieved from https://www150.statcan.gc.ca/t1/tbl1/ $\mathrm{fr} / \mathrm{tv}$.action?pid=1710000501\&pickMembers\%5B0\%5D=1.6\& pickMembers $\% 5 \mathrm{~B} 1 \% 5 \mathrm{D}=2.1 \&$ cubeTimeFrame.startYear $=2016 \&$ cubeTimeFrame.endYear $=2020 \&$ referencePeriods $=20160101 \%$ 2C20200101

Urban, M., Cardini, A., \& Flórez Romero, R. (2018). It takes more than a village. Effective early childhood development, education and care services require competent systems. Buenos Aires. Retrieved from https://t20argentina.org/publicacion/it-takes-more- than-avillage-effective-early-childhood-development-education-andcare-services- require-competent-systems/

Urban, M., Vandenbroeck, M., Van Laere, K., Lazzari, A., \& Peeters, J. (2012). Towards competent systems in early childhood education and care. Implications for policy and practice. European Journal of Education, 47(4), 508-526. Retrieved from https://doi.org/10. 1111/ejed.12010

Voci, A., Veneziani, C. A., \& Fuochi, G. (2019). Relating mindfulness, heartfulness, and psychological well-being: the role of selfcompassion and gratitude. Mindfulness, 10(2), 339-351. Retrieved from https://doi.org/10.1007/s12671-018-0978-0

World Health Organisation (WHO). (2020). Listings of WHO's response to COVID-19. Retrieved from https://www.who.int/ news/item/29-06-2020-COVIDtimeline

Xiong, J., Lipsitz, O., Nasri, F., Lui, L. M., Gill, H., Phan, L., et al. (2020). Impact of COVID-19 pandemic on mental health in the general population: A systematic review. Journal of affective disorders, 277, 55-64. https://doi.org/10.1016/j.jad.2020.08.001

Publisher's Note Springer Nature remains neutral with regard to jurisdictional claims in published maps and institutional affiliations. 